\title{
RESHAPING AGRIFOOD SYSTEMS TO ACHIEVE MULTIPLE DEVELOPMENT GOALS
}

Shenggen Fan and Keijiro Otsuka

Today, agrifood systems are undergoing remarkable changes, reflected in the modernization of food value chains and rural transformation responding to urbanization, income growth, and expansion of international trade. At the same time, agrifood systems are expected to contribute to a wide range of development goals, reaching beyond agricultural productivity growth and food security. Thus this book has examined key issues using new lenses reflecting the rapidly changing world, such as nutrition, household decisionmaking behavior (related not only to gender but also to credit and insurance), natural resource management (including land, forests, and water), climate change, reprioritization of agricultural research, and political economy. Major findings from regional chapters (Chapters 3-7) were summarized in Chapter 8, while this chapter aims to synthesize the thematic chapters (Chapters 9-21). We highlight priority areas for action to reshape agrifood systems for achieving multiple development goals, including reductions in poverty and malnutrition, without harming the environment.

\section{Agricultural Development and Transformation of Agrifood Systems}

Despite the different pathways regional agrifood systems have taken over the past decades, rapid urbanization is occurring in almost all developing countries. This is driving structural change as workers move from rural to urban areas and leave agriculture for other sectors with higher labor productivity and incomes. Urbanization and urban income growth generate increased demand for agricultural products, while also shifting the composition of products demanded. This affects agrifood systems, as urban households consume a lower share of cereals, fats, and oils but higher shares of meat, dairy, fish, fruits, and vegetables as well as processed foods. While the latter products are generally nutritious, their prices are relatively high in developing countries, reflecting inadequate investment in research and development (Chapter 10). 
Furthermore, governments in developing countries have a role to play in diversification of agricultural production and consumption, by investing, for example, in community health/nutrition initiatives.

Urbanization has also led to an increase in the share of poor people living in urban areas, likely driven by an inflow of poorer migrants or an overcrowding of low-income urban areas (Chapter 9). At the same time, transformation of the rural economy occurred in some regions, marked by increased productivity in staple crop farming, introduction of more profitable high-value agricultural products, better employment opportunities in rural nonfarm sectors, and migration to urban areas (Chapter 11). Since the farming environment is heterogeneous across major regions and even within a community, and since high-value products are usually new to farmers, the role of applied research and extension in disseminating environment-specific technological and managerial information to farmers has become critically important. Innovation is key to the development of agro-processing industries, so investment in human capital of entrepreneurs and farmers is indispensable (Chapter 11). To the extent that innovation by private individual initiatives is imitated, collective action plays an important role in internalizing the benefits of innovation.

As agrifood systems transform, food value chains transform as well. Traditional food value chains are fragmented and spatially short, with a low urban share and a high share of staple crops and grains. As economies continue to develop, food value chains become spatially longer, with a rising urban share, growth in the midstream of the value chain, and more diversified products. In the modern era, food value chains are spatially long, with a high urban share, expanded transportation, and development of peri-urban production. Growing urban market demand, especially for nongrain products, is transmitted to rural areas through rural-urban supply chains. The rapid development of nongrain and processed food markets in both urban and rural areas creates profitable new opportunities for actors along the value chain, including farmers, wholesalers, and processors (Chapter 12). Additional modern trends emerge, including disintermediation and multinationalization of the food value chain. This is reflected in expanding international trade of agricultural products, which is also supported by decreased distortion of agricultural markets (Chapter 13).

This transforming context of agrifood systems and value chains has significant implications for and is simultaneously affected by household decisionmaking behavior, particularly in relation to gender dynamics. Women have less access to agricultural land and other assets in developing countries, as men traditionally own or control land more often than women do (Chapter 15). 
In addition, women tend to spend more resources on health and nutrition as well as education of children. Thus women's constrained access to productive resources may lead to underinvestment in these areas, even though the rate of return to such investment increases with the transformation of agrifood systems.

Although access to credit and insurance is critical for households to smooth consumption over time under risky production environments, to purchase modern inputs, and to invest in improving long-term productivity, many households still lack access to institutional finance. An important new financial institution, mobile banking, is particularly common in East Africa. While certain transactions, such as payments and remittance transfers, can be conducted via mobile banking, extension of credit cannot. To improve access to credit and insurance, institutional innovations-for example, bank finance and microfinance, the use of satellite imagery for monitoring crop damage, and index insurance programs-will be key (Chapters 16 and 17).

Understanding household behaviors will be crucial to facilitate gender equity. Moreover, to ensure inclusiveness of modern agrifood systems that leaves no one behind, investments in child schooling, nutrition, and health as well as in farm equipment and nonfarm businesses will be needed. Yet important aspects of household decision-making are not always properly accounted for in the macroeconomic literature; these include gender dynamics, liquidity or credit constraints (mismatches between the timing of income and expenditures), and risk (for which insurance is an important policy instrument).

With the population continuing to grow, while additional available land for agriculture is declining, there is no doubt that maintaining or improving natural resources already in use for agriculture-for example, land, water, and trees-is critical for food security. There are numerous management practices that can safeguard or enrich the natural resource base, but their application in developing countries needs to be greatly expanded. There are many mechanisms to improve incentives to adopt desirable management practices, but a key one will be the improvement of tenure securities over resources (Chapter 18). It is important to note, however, that there is no single tenure policy that will prove to be the best option in all countries, all locations within a country, or even within a community because of environmental, cultural, and institutional heterogeneities.

Agriculture continues to contribute to climate change, and climate change impacts agrifood systems. Climate impacts involve many dimensions, including changes in precipitation patterns, changing frequency and intensity of extreme weather events, changing patterns of pests and diseases affecting 
crops, livestock, and humans, rising sea levels, and glacial melting. As a result, projection models indicate that, for example, by 2050 climate change will reduce yields of maize, rice, wheat, and soybeans by an average of 11 percent or so worldwide and increase real prices by 20 percent, relative to the hypothetical reference case of no climate change (Chapter 19). Also worrisome is the growing scarcity of irrigation water for agriculture, which is affected by climatic volatility, urbanization and industrialization, and diet shift toward water-intensive foods (Chapter 20). Continuing the excessive use of water in agriculture will not be a sustainable option. Strengthening property rights on environmental resources, accelerating investment in irrigation, and improving water management are necessary to preserve and improve the stock of water resources.

Using new scientific possibilities, agricultural research must address issues arising from global-level transformations, including (1) raising farm productivity to feed the growing population under declining natural resources (Chapters 18, 19, and 20); (2) dealing with heterogeneity of natural and cultural environments by strengthening national agricultural research and extension systems (Chapters 11 and 18); (3) developing value-added agriculture to raise farmers' incomes and to supply healthy foods to consumers (Chapters 10, 11, and 12); and (4) facilitating adaptation to and mitigation of climate change (Chapter 19). A clear understanding of the major features of agricultural technology is critical in designing policies to allow agricultural research to be a source of value and benefit for both farmers and consumers, while addressing global challenges like climate change and degradation and depletion of natural resources. In order to achieve these goals, it is particularly important to establish effective linkages between public and private research and among international agricultural research systems represented by CGIAR, national agricultural research systems, and decentralized extension systems. We expect that the ongoing information and biotechnology revolutions are likely to transform agriculture in significant ways, and our challenge is to make this transformation beneficial to the poor, consumers, society as a whole, and the environment.

\section{Transforming the Agrifood System for Achieving the UN Sustainable Development Goals}

To engage in a changing global context and transforming agrifood systems, an integrated food systems approach is needed. The approach will need to consider traditional issues that remain important, emerging challenges in 
formulating policies, and a way forward for agrifood systems, many of which were discussed in the previous chapters. Improving agricultural productivity, employment, and livelihoods of smallholders, which are among the issues that have been the focus in agricultural development in past decades, will still be crucial to address challenges that face agrifood systems. At the same time, health and diets, the environment, and climate change have grown in prominence within the food systems approach, with a recognition that these issues are inseparably related to food production and global agrifood systems (Willett et al. 2019; IPCC 2018, 2019a, 2019b). If consumers' dietary habits change, the food production system must change. Consequently, greenhouse gas (GHG) emissions will change, as will the ecosystem, leading to changes in climate. The challenge for modern agrifood systems is how to mitigate climate change and preserve or improve ecosystems, while delivering healthy foods to consumers. To cover these multiple facets and contribute to multiple development goals, the approach should seek to reshape agrifood systems to be nutrition- and health-driven, productive and efficient, environmentally sustainable and climate-smart, inclusive, and business-friendly.

A nutrition- and health-driven system that uses nutrition as goals and promotes healthy diets is important, considering the persistence of and increases in multiple forms of malnutrition and diet-related diseases related to food systems. The food system needs to be productive and efficient by producing more food with fewer resources and reducing food waste and loss to efficiently meet current and future needs. The system must be environmentally sustainable and climate-resilient to minimize negative environmental impact, including but not limited to land degradation, deforestation, and overuse of species. The global food system needs to be inclusive, especially of smallholder farmers, women, and youth, who often lack access to assets and markets and face risk of exclusion from modern food value chains. Last, the food system should be business-friendly, with an enabling environment for well-functioning markets, partnerships, and a vibrant private sector. To reshape agrifood systems in light of the growing urgency and consensus in the global community toward the food systems approach, we propose the following priority areas for action based on the results of diverse analyses in the preceding chapters.

\section{Empower Consumers with Knowledge}

To improve nutrition, knowledge and understanding of the links between nutrition and health must reach consumers (Chapter 10). Understanding various barriers to consumer knowledge and addressing them with proper education and knowledge dissemination is essential to ensure enhanced nutritional 
outcomes (Willett et al. 2019). It is equally important that consumers are equipped with nutrition knowledge to better leverage social protection programs, such as cash transfers (de la Paz 2016).

While many strategies for consumer education are available, some successful experiences can be helpful in providing best practices and lessons learned. One such experience was in Bangladesh, where nutrition training sessions and cooking contests were held to test their impact on nutrition knowledge and subsequent dietary changes toward healthier consumption (Kramer 2017). And according to a randomized controlled trial study in Malawi, provision of information on child nutrition to mothers improved not only child nutrition but also health and food expenditures (Fitzsimons et al. 2016). These interventions were low-cost and successful in improving knowledge and education on nutrition. However, the study found that complementary interventions are needed to further change consumer behavior toward healthier diets.

In addition, many other potential avenues of education-such as nontechnical publications, public informal debates, blogs, webinars, media, targeted community training programs, nutritional curriculum development, research grants, and fellowship promotion — are available (Fan, Yosef, and PandyaLorch 2018). Targeting education to women and children will be particularly important in these campaigns. These two population subsets are those most affected by malnutrition and should therefore be well educated on the importance of good nutrition and how to attain it (Chapters 10 and 15). Women often hold considerable influence in the nutrition and health outcomes of a household and should be inclusively engaged with education. Food system regulations, both mandatory and voluntary, are an important complement to new technologies and consumer awareness for nutrition and health. The nutritional content and safety of foods is often unknown by the consumer, especially after processing or if food is purchased and consumed away from home. Labeling and quality standards based on nutrient testing and other food safety measures are therefore needed to improve consumers' awareness so that they can make good nutritional choices that will benefit their health. Information and communications technologies have also improved surveillance of food products through adulteration testing and traceability.

\section{Transform Farmers into Entrepreneurs}

The policies pursued under the proposed agrifood systems approach need to be inclusive of social, economic, and environmental issues and of all sections of the population, especially the vulnerable and marginalized. Particularly important will be investments in human capital of subsistence-oriented 
smallholder farmers (Chapter 11). Investment in their human capital improves household income as well as development of rural nonfarm sectors. Schooling and health, in particular, affect farming efficiency, nonfarm employment, and migration.

In addition, human capital investment, including the entrepreneurial training of farmers, is key to stimulating new innovations, such as the introduction of nutritious high-value products by farmers themselves (Chapter 11). Particularly important is the ability to "deal with disequilibria" (Schultz 1975) - that is, the ability to learn new technologies, products, and production methods, and to analyze the changing structure of market demands. Farmers cannot be made significantly better-off if they passively follow the instruction given by marketing agents. Unless farmers are transformed from subsistence-oriented to entrepreneurial, so that they can bargain with marketing agents (for example, agro-processors, traders, and supermarkets), an inclusive modern agrifood system can never be constructed. To support more efficient value chains linking rural and urban areas, institutional innovation such as the formation of producer cooperatives is often required (Chapter 11; Hashino and Otsuka 2016). A good example is the coffee unions of Ethiopia that provide marketing and input-supply services and connect producers to export markets (da Silva and Fan 2017). Producer cooperatives also play a key role in the introduction of new high-value products to rural areas, as these reduce the transaction costs between buyers and a large number of smallholder farmers (Chapter 11).

\section{Incentivize the Private Sector}

Private sector leadership is critical as urbanization and market growth around the world provide profitable business opportunities. Business interests have the power to improve nutritional outcomes by boosting demand for nutritious products through appropriate marketing and pricing. While there is great potential in business-friendly agrifood systems, it is by now widely recognized in the literature that the managerial inability of enterprise managers is a major constraint on the growth of enterprises and, consequently, local industries in developing countries (Bloom et al. 2012; Sonobe and Otsuka 2011, 2014).

Since new valuable information spills over, the social benefit of introducing fresh ideas is larger than the private benefit. Herein lies opportunity for government and aid agencies to invest, through training, in the managerial human capital of enterprise managers, who can appropriately respond to changing demand and create improved marketing systems. Using randomized controlled trials, several studies demonstrated that management training 
improves enterprise performance significantly (Bloom et al. 2013; Mano et al. 2012; Higuchi, Mhede, and Sonobe 2019). Establishment of industrial clusters or industrial parks, for example, can also help create hubs for vibrant development of agro-processing industries (Chapter 11). Improvements in infrastructure, transportation, and communications systems along the supply chain will be important for reducing food loss and waste and creating a food system that is responsive to changing consumer demands across rural and urban areas (Fan 2016).

The public sector can also support private stakeholders by setting quality standards, maintaining market institutions, and introducing tax incentives or other structures to effectively encourage the supply of healthy foods as well as fostering innovation and providing technical support. If markets for foods high in micronutrients and free of undetectable contaminants are to function and thrive, sellers must have the ability to signal quality. Low- and variablequality products will remain in the market until new technologies and institutions permit quality standards to be set and enforced (Masters, Nene, and Bell 2017). Therefore, governments and trade associations need to be equipped and capable of regulating business practices and production methods that affect nutrition and health (Fan, Yosef, and Pandya-Lorch 2018). We should eventually aim to construct a food system that has strong links with private sector parties along the supply chain and facilitates partnerships between private sector actors and public institutions, international organizations, and civil society organizations. Adequate regulatory mechanisms to mitigate market shocks along with information and communications infrastructure can contribute to a well-functioning food system to engage the private sector (Fan 2016; IFPRI 2016).

\section{Reprioritize Research and Development}

Relatively few resources have been invested in agricultural research and development (Chapter 21). Probably the best indicator of underinvestment in research on nutrition-rich, high-value products in developing countries is how exceedingly high-priced these products are (Chapter 10). This is notable given the remarkable increases in demand for nutritious foods and increasing interest in the agriculture-nutrition nexus. It is true that nutrition-driven and nutrition-sensitive technologies, such as biofortification, have been developed. They can potentially play an important role by increasing the nutrition density in crops (HarvestPlus 2017). To strengthen linkages between agriculture, nutrition, and health, it is essential to invest in agricultural research and development, particularly for nutritious foods. 
There also are potential technology options and cultivation practices that can substantially mitigate and adapt to climate change (Chapters 19 and 20; IPCC 2018, 2019a; Willett et al. 2019). For mitigation, resource-saving technology is needed, whereas for adaptation, technologies resistant to harsh climates are needed (Chapter 21). Also needed is the development of technology to use renewable resources, including biomass. In particular, the following are important technological innovations:

1. Technology or crop varieties (including fruits, vegetables, and beans) resistant to drought, heat, submergence, and salinity.

2. Input-saving technologies and management practices, including water, nitrogen fertilizer, and feed.

3. Technology to monitor activities leading to GHG emissions and to assess their impacts.

4. Cost-effective bioenergy, whose production does not compete with food production.

These technologies are global public goods, and global institutions such as the CGIAR must undertake research with the aim of mitigating and adapting to climate change. ${ }^{1}$ Yet because of the environmental heterogeneity, adaptive research by national agricultural research systems and decentralized local extension systems are also an integral part of the innovation system. If technology development is the ultimate solution for climate change and the achievement of sustainable development, we must recognize that proper pricing of resources is the key to inducing the desired resource-saving technological changes. For example, restricting the use of fossil fuels, which will lead to increased energy prices, will stimulate the development of energy-saving technology in general and bioenergy in particular. Bioenergy deployment offers significant potential for climate change mitigation, which requires extensive use of agricultural residues and second-generation biofuels extracted from planted fast-growing tree species (IPCC 2018, 2019a). To avoid the risk of reducing food production, such "renewable biomass" whose production does not conflict with food production should be used. Although often unnoticed, technology to monitor GHG emissions and assess their impacts is a particularly important global public good (Chapter 19). Development of such

1 This does not imply that CGIAR has not undertaken relevant research (see, for example, Rosenstock et al. [2016] for the analysis of methods for measuring GHG emission). 
technology will help implement appropriate policies to reduce GHG emissions, such as carbon tax, which is in line with the Coase Theorem (Coase 1960) that indicates that lower transaction costs tend to lead to socially improved resource allocations.

We will be able to transform agriculture to help achieve the UN Sustainable Development Goals only if the global community is willing to invest sufficiently to successfully develop a new set of global public goods. Investment in research and development is particularly necessary to fill extensive gaps in the evidence base regarding the effectiveness of actions for shifting diets in more healthy and sustainable directions. Research and development will also need to shift more toward improvements in health and environmental sustainability, and to focus on achieving multiple wins. Rigorous estimation methods that are being largely used in applied microeconomics should be leveraged and further strengthened. Particular attention should be paid to knowledge gaps for low- and middle-income countries, where there is a dearth of evidence on the linkages among agriculture, nutrition, health, and ecosystems (Willett et al. 2019).

\section{Internalize Environment and Climate Effects}

Achieving high productivity in agriculture and maintaining its growth in a way that does not degrade natural resources such as water, soil, and natural vegetation are major challenges to achieving sustainable agriculture (Chapters 18 and 20). We must note that management of water, soils, application of manure, conversion of forestland and woodland to farmland, and raising ruminants all affect the emission and sink of GHGs, which give rise to global externalities or climate change. Thus we must consider policies to reduce global negative externalities and to promote positive ones by improving the management of natural resources and the global climate. For example, irrigation water is often a local or regional common-pool resource and its use is free, which is bound to result in socially excessive use. A fundamental cause of excessive use of water is the absence of appropriate pricing that reflects its scarcity value. Thus, to reduce water use, a low-cost method of measuring its use is needed to apply volumetric water pricing to individual farmers or their group (for instance, a water users' association, which in turn charges water fees to individual farmers).

In addition, incentives to preserve and improve the stock of natural resources hinge on security of land rights, because they affect the probability that future benefits accrue to those who invest in the future. There is a host of empirical evidence that devolving forest property rights from the state to 
communities contributes to the sustainable management of forest resources (Chapter 18). The establishment of clear land rights, be they individual or communal, is also essential for sustainable management of farmland and other natural resources. Policy reforms, especially granting individual land rights to women, will be crucial for inclusive growth of agriculture (Fan 2016; Chapters 15 and 18).

Furthermore, agriculture must contribute to massive reductions in GHG emissions or even to sequestration of greenhouse gases. Major potential activities to reduce GHG emissions include reduction in deforestation, increase in forest cover and agroforestry, improvement of agricultural and livestock management, and introduction of sustainable bioenergy (Chapters 18-21; IPCC 2019a). The payment for ecosystem services (Farley 2012; Bennett and Gosnell 2015) — that is, the "price" paid for suppliers of ecosystem services as compensation for their continued provision of such services-is an application of the Coase Theorem to the environmental issue. Since forests and other ecosystems provide global externality in terms of sink of $\mathrm{CO}_{2}$ and preservation of biodiversity, it is reasonable for the global community to pay landowners for the amount of global benefits.

Cost-effective methods to reduce emissions of nitrous oxide could include imposing taxes on nitrogen fertilizer and biomass burning and development of nitrogen-efficient crop varieties. Taxes could also be placed selectively on purchased feed, as the use of improved feed and dietary additives and improved breeds with higher productivity and lower methane emissions can contribute to reducing GHG emissions. The promotion of precision agriculture, particularly microdosing, can be an important complement to increase crop yields with less fertilizer (ICRISAT 2015). Global institutions, such as the Global Environmental Facility, will also need to be part of building a global consensus on simple practical rules on the amount of taxation and payments for ecosystem services, which are needed to achieve sustainable world agriculture.

\section{Make Key Stakeholders Accountable}

It must be clearly recognized that agrifood systems encompass the entire range of actors and their interlinked value-adding activities throughout the worldfrom food production, processing, and consumption to the broader economic, social, and natural environments in which these diverse food systems are embedded. Although preceding chapters did not explicitly discuss the issues of intragovernmental and intergovernmental collective actions and governance, it is obvious that in order to transform and reshape agrifood systems for global benefits, stakeholders will be required to undertake unprecedented 
collective action based on a solid understanding of the political economy in the agrifood system at the local, national, and global levels. This will require effective governance mechanisms at all levels under an integrated approach that cuts across political, sectoral, and geographical boundaries. To facilitate such an approach, we must establish formal and informal collaborative interactions and structures among governing groups, including various UN bodies and specialized agencies, to focus on cross-sectoral issues like healthy and sustainable diets. Relevant sectors and ministries at the national level, such as ministries of health, agriculture, and environment, will need to coordinate their efforts.

Given the deteriorating global environment and increasing emission of greenhouse gases by developing countries, now amounting to more than half of total global emissions (IPCC 2018), both developed and developing countries must contribute to the mitigation of climate change. However, considering that large developed economies are largely responsible for climate change, they should be held accountable and ought to consider how they can compensate developing countries for loss and damage due to climate change. Enhanced monitoring ability and government accountability are important to track our progress, and we must leverage the data revolution and big data analytics for quality, evidence-based evaluation. Backed by high-quality, timely data, stakeholders will need to track progress toward multiple development goals and use data to guide policy action. For example, tools like the Women's Empowerment in Agriculture Index, which measures women's empowerment, agency, and inclusion in agriculture, will play a critical role in identifying current gaps and constraints.

To sum up, in order to achieve multiple goals of sustainable, healthy, and inclusive agricultural development all over the world, national, regional, and global collaborative efforts are clearly called for to reshape global agrifood systems in line with the recommendations proposed in this chapter.

\section{References}

Bennett, D. E., and H. Gosnell. 2015. "Integrating Multiple Perspectives on Payments for Ecosystem Services through a Social-Ecological Systems Framework." Ecological Economics 116: 172-181.

Bloom, N., B. Eifert, A. Mahajan, D. McKenzie, and J. Roberts. 2013. “Does Management Matter? Evidence from India." Quarterly Journal of Economics 128 (1): 1-51. 
Bloom, N., C. Genakos, R. Sadun, and J. Van Reenen. 2012. "Management Practices across Firms and Countries." Academy of Management Perspectives 26 (1): 12-33.

Coase, R. H. 1960. “The Problem of Social Cost.” Journal of Law and Economics 3: 1-44.

da Silva, J. G., and S. Fan. 2017. “Smallholders and Urbanization: Strengthening Rural-Urban Linkages to End Hunger and Malnutrition.” In 2017 Global Food Policy Report, 14-23. Washington, DC: International Food Policy Research Institute (IFPRI).

de la Paz, J. 2016. "Channeling Social Protection Programs for Improved Nutrition in Bangladesh." IFPRI blog, July 5, IFPRI, Washington, DC.

Fan, S. 2016. "Food Policy in 2015-2016: Reshaping the Global Food System for Sustainable Development." In 2016 Global Food Policy Report, 1-11. Washington, DC: IFPRI.

Fan, S., S. Yosef, and R. Pandya-Lorch. 2019. Seizing the Momentum to Reshape Agriculture for Nutrition. Wallingford, UK: CABI.

Farley, J. 2012. “Ecosystem Services: The Economics Debate.” Ecosystem Services 1 (1): 40-49.

Fitzsimons, E., B. Malde, A. Mesnard, and M. Vera-Hernández. 2016. “Nutrition, Information, and Household Behavior: Experimental Evidence from Malawi." Journal of Development Economics 122: 113-126.

HarvestPlus. 2017. Driving Impact: 2016 Annual Report. Washington, DC: IFPRI.

Hashino, T., and K. Otsuka. 2016. Industrial Districts in History and the Developing World. Dordrecht, Netherlands: Springer.

Higuchi, Y., E. P. Mhede, and T. Sonobe. 2019. “Short- and Medium-Run Impacts of Management Training: An Experiment in Tanzania." World Development 114: 220-236.

ICRISAT (International Crops Research Institute for Semi-Arid Tropics). 2015. Fertilizer Microdosing Increases Agriculture Productivity. Project Policy Brief 2. Niamey, Niger

IFPRI (International Food Policy Research Institute). 2016. "Accelerating the Contribution That Nutrition's Underlying Drivers Make to Nutrition Improvements.” In Global Nutrition Report 2016: From Promise to Impact: Ending Malnutrition by 2030, 60-75. Washington, DC.

IPCC (Intergovernmental Panel on Climate Change). 2018. Global Warming of $1.5^{\circ} \mathrm{C}$. An IPCC Special Report on the impacts of global warming of $1.5^{\circ} \mathrm{C}$ above pre-industrial levels and related global greenhouse gas emission pathways, in the context of strengthening the global response to the threat of climate change, sustainable development, and efforts to eradicate poverty.

- 2019a. Climate Change and Land. An IPCC Special Report on climate change, desertification, land degradation, sustainable land management, food security, and greenhouse gas fluxes in terrestrial ecosystems. 
-2019b. IPCC Special Report on the Ocean and Cryosphere in a Changing Climate.

Kramer, B. 2017. Cooking Contests for Healthier Recipes: Impacts on Nutrition Knowledge and Behaviors in Bangladesh. IFPRI Discussion Paper 1661. Washington, DC: IFPRI.

Mano, Y., A. Iddrisu, Y. Yoshino, and T. Sonobe. 2012.“How Can Micro and Small Enterprises in Sub-Saharan Africa Become More Productive? The Impacts of Experimental Basic Managerial Training." World Development 40 (3): 458-468.

Masters, W. A, M. D. Nene, and W. Bell. 2017. “Nutrient Composition of Premixed and Packed Complementary Food for Sale in Low- and Middle-Income Countries: Lack of Standards Threatens Infant Growth." Maternal \& Child Nutrition 13 (4): 12421-12431.

Rosenstock, T. S., M. C. Rufino, K. Butterbach-Bahl, E. Wollenberg, and M. Richards, eds. 2016. Methods for Measuring Greenhouse Gas Balances and Evaluation Mitigation Options in Smallholder Agriculture. Dordrecht, Netherlands: Springer.

Schultz, T. W. 1975. “The Value of Ability to Deal with Disequilibria." Journal of Economic Literature 13 (3): 827-846.

Sonobe, T., and K. Otsuka. 2011. Cluster-Based Industrial Development: A Comparative Study of Asia and Africa. Hampshire, UK: Palgrave Macmillan.

- 2014. Cluster-Based Industrial Development: Kaizen Management for MSE Growth in Developing Countries. Hampshire, UK: Palgrave Macmillan.

Willett, W., et al. 2019. "Our Food in the Anthropocene: The EAT-Lancet Commission on Healthy Diets from Sustainable Food Systems.” Lancet 393 (10170): 447-492. 